\title{
Os movimentos feministas e o processo da Reforma Sanitária no Brasil: 1975 a 1988
}

\author{
Feminists movements and the process of Sanitary Reform in Brazil: \\ 1975-1988
}

Paloma Silva Silveira', Jairnilson Silva Paim', Karla Galvão Adrião

DOI: 10.1590/0103-11042019S820

\begin{abstract}
RESUMO O presente ensaio visou apresentar reflexões iniciais de uma pesquisa mais ampla ainda em curso sobre as relações entre os movimentos feministas e a Reforma Sanitária Brasileira no período de 1975 a 1988. Tema pouco estudado em uma conjuntura adversa, a ditadura militar, mas também marcada por efervescências políticas e sociais, a partir de uma pesquisa documental preliminar, foram identificados eventos e documentos que indicam diálogos entre esses dois movimentos sociais. Engajados na luta pela redemocratização social e democratização da saúde, os movimentos feministas e sanitário apresentaram propostas convergentes exemplificadas pela formulação e tentativa de implementação do Programa de Assistência Integral à Saúde da Mulher (Paism). Primeira política pública de saúde que traz a integralidade, um dos princípios do Sistema Único de Saúde, no Paism, encontram-se proposições defendidas pelo Movimento Sanitário e vinculadas às pautas feministas na saúde. Entretanto, esses trânsitos parecem ter sido marcados por algumas dificuldades relacionadas com a conjugação das denominadas questões mais 'amplas' com as 'específicas' e os desafios para elaboração de pautas comuns entre os dois movimentos. Reconhece-se, portanto, a complexidade da temática. Ousa-se apresentar essas reflexões para explicitar os diálogos, as conquistas alcançadas e, talvez, contribuir para a construção de estratégias renovadas de luta pelo direito à saúde.
\end{abstract}

PALAVRAS-CHAVE Mulheres. Feminismo. Política de saúde. Direito à saúde. Democracia.

\begin{abstract}
This essay aims to present reflections from a larger, ongoing research project on the relationship between feminists movements and the Brazilian Sanitary Reform in the period between 1975 and 1988. It is a little-studied topic in an adverse political scenario, namely, the military dictatorship, but a period also marked by political and social effervescence. It was based on a preliminary archival research that identified events and documents that indicate dialogues between these two social movements. Engaged in the struggle for redemocratization and the democratization of health, these movements presented convergent proposals exemplified by the formulation and attempts of implementation of the Program for Integral Care for Women's Health (Paism). The first public policy to promote integrality, one of the principles of the Unified Health System, in the Paism we find propositions defended by the Sanitary Reform Movement and linked to feminist issues in healthcare. However, that dialogue appears to have been marked by some difficulties related to the synchronization of the so-called 'broader' issues with 'specific' ones, and the challenges for the elaboration of common issues between the two movements. We recognize, therefore, the complexity of the topic. We dare to present these reflections in order to make explicit the dialogues, the successes achieved, and to contribute to the construction of renewed strategies of struggle for the right to health.
\end{abstract}

KEYWORDS Women. Feminism. Health policy. Right to health. Democracy.

2 Universidade Federal de Pernambuco (UFPE) Recife (PE), Brasil.

1 Universidade Federal da Bahia (UFBA), Instituto de Saúde Coletiva (ISC) Salvador (BA), Brasil. palomasilveira25@gmail. com 


\section{Introdução}

Podemos compreender a Reforma Sanitária Brasileira (RSB) como um movimento social emergido em meados da década de 1970, que está ainda em processo de institucionalização no Brasil1. O denominado Movimento Sanitário reuniu diferentes segmentos da sociedade civil e tinha como bandeira de luta o direito à saúde, elegendo o lema que 'saúde é democracia'2-4. A criação do Centro Brasileiro de Estudos de Saúde (Cebes), em 1976, é considerada um marco. Em 1977, a revista 'Saúde em Debate', vinculada ao Cebes, defendeu a saúde como 'direito de cada um/a e de todos/as os/as brasileiros/ as', apontando para a importância da reestruturação da atenção à saúde e que esta fosse comprometida com a modificação das reais condições de saúde da população. $\mathrm{O}$ Cebes, desde sua fundação, problematizava alguns aspectos fundamentais da reforma, como: a unificação dos serviços de saúde, a participação social das/os cidadã/os e a ampliação do acesso a serviços de qualidade'.

Na década de 1970, o Brasil estava sob regime militar. Crises em vários setores, incluindo a saúde marcaram esse período. As condições precárias de saúde e as ineficazes respostas do Estado desencadearam mobilizações. Diversos movimentos sociais na saúde e também fora desta, como, por exemplo, os movimentos feministas, lutaram contra a ditadura participando e organizando diferentes ações para a redemocratização do País e para democratização da vida social1,2,5:

Voltando aos anos 70 é interessante observar, como o faz Barsted (1992), que os temas da reprodução e da sexualidade não inauguraram a primeira pauta do feminismo contemporâneo brasileiro. A conjuntura política do regime militar, a aliança com a Igreja e com os partidos de esquerda eram fundamentais na luta contra o arbítrio e, em função disto, as questões referentes à sexualidade $\mathrm{e}$ reprodução tiveram que ficar estrategicamente fora do emergente discurso feminista. Um governo civil eleito pelo povo é a grande aspiração do momento6(383-384).

De modo geral, os movimentos sociais podem ser definidos como ações sociopolíticas de caráter conservador ou progressista, construídas por coletivos de distintos segmentos que surgem em um determinado momento sócio-histórico da sociedade civil e que têm a potência para desencadear transformações sociais ${ }^{7}$. Assim, nesse período, a consolidação da democracia era o objetivo político principal, sendo esta entendida como o pilar para a construção de uma nova sociedade. Configurando-se uma nova conjuntura política, era importante a organização dos movimentos sociais para a obtenção e garantia dos direitos sociais na Nova Constituição $0^{6}$.

Em 1986, um ano após o término da ditadura militar, foi realizada a 8 a Conferência Nacional de Saúde (CNS), e a Reforma Sanitária foi a expressão, que em um primeiro momento, caracterizou o movimento de democratização da saúde. Evento emblemático para o movimento sanitário, em seu relatório final, consta o que se compreendia como Reforma Sanitária':

Em primeiro lugar, ficou evidente que as modificações necessárias ao setor saúde transcendem os limites de uma reforma administrativa e financeira, exigindo-se uma reformulação mais profunda, ampliando-se o próprio conceito de saúde e sua correspondente ação institucional, revendo-se a legislação no que diz respeito à promoção, proteção e recuperação da saúde, constituindo-se no que está convencionado a chamar Reforma Sanitária8(2).

Ao adotar um conceito amplo de saúde "resultante das condições de alimentação, habitação, educação, renda, meio ambiente, trabalho e transporte, emprego e lazer, liberdade, acesso e posse da terra e acesso a serviços de saúde. É assim, antes de tudo, o resultado das formas de organização social da produção, as quais 
podem gerar grandes desigualdades de nível de vida"8(4), a VIII CNS concebia a RSB para além de uma reforma administrativa e financeira, ou mesmo restrita ao setor saúde. Contudo, no processo de redemocratização, quando o governo federal estabeleceu a Comissão Nacional da Reforma Sanitária (CNRS), em seus diversos documentos estavam presentes uma concepção da RSB limitada a modificações no sistema de serviços de saúde. Em oposição a essa percepção, alguns atores e atrizes do Movimento Sanitário debateram a importância do que denominavam como uma 'totalidade de mudanças', a partir de quatro dimensões interligadas: a específica, a institucional, a ideológica e das relações de produção'.

A dimensão específica corresponde à própria dinâmica do fenômeno saúde/doença nas populações, ao conhecimento da situação de saúde, da experiência acumulada, da comparação com outros povos, entre outros elementos. A dimensão institucional se refere a todas as instituições que atuam no setor saúde, desde a fabricação de insumos até aquelas que formam recursos humanos. A terceira dimensão é a ideológica. Nesta conjugam-se valores, concepções e preconceitos produzidos em um momento histórico sobre a situação sanitária. Por fim, a dimensão das relações de produção que corresponde à determinação social das necessidades de saúde. A análise da RSB a partir dessas dimensões possibilitava a sua articulação com a estrutura social: infraestrutura econômica e superestrutura político-ideológica'.

Dessa forma, a RSB tem sido analisada enquanto um processo sócio-histórico, como uma reforma social que transcende a dimensão setorial ${ }^{4}$ e pensada por alguns autores como práxis de reforma social geral para alcançar a revolução do modo de vida ${ }^{2}$. Paim², ao mencionar a revolução do modo de vida, refere-se ao conceito desenvolvido por Heller ${ }^{9}$. A filósofa húngara o apresenta atrelado a um tipo de práxis, distinguindo quatro: reforma parcial, reforma geral, movimentos políticos revolucionários e revolução social total/revolução do modo de vida.
A práxis denominada de reforma parcial corresponde a um tipo de atividade que se propõe transformar setores específicos da sociedade, focalizando em determinadas situações. Nesses casos, as ações das massas não duram muito tempo, podendo se converter em veículos de manipulação, pois criam um simulacro de transformação da ordem social. O segundo tipo de práxis, a reforma geral, propõe a transformação de toda a sociedade por meio de reformas parciais. Os movimentos para a reforma geral são organizados com uma ampla base de massas e não deixam de existir depois da realização de uma reforma parcial ${ }^{2}$.

Já o terceiro tipo de práxis se realiza nos movimentos políticos revolucionários e tem como objetivo a transformação radical de toda a sociedade pela conquista do poder político. O que impulsiona o movimento é uma parcela da população, especificamente, uma elite revolucionária com o respaldo ativo das massas. Entretanto, com a vitória, desenvolve-se um movimento de refluxo, a atividade das massas se torna passiva, e o modo de vida da maioria da população permanece inalterado. O quarto tipo de práxis é a revolução social total, que significa ao mesmo tempo a revolução do modo de vida. Essa práxis implica um movimento de segmentos cada vez mais amplos da população, e a vida cotidiana das pessoas sofre uma transformação como consequência de sua implicação ${ }^{2,9}$.

Apesar de ter sido pensada como práxis de reforma social geral sendo teorizada para alcançar a revolução do modo de vida, a RSB apresentaria como desenlace uma reforma parcial setorial e institucional, evidenciada pelos 30 anos do Sistema Único de Saúde (SUS) ${ }^{10}$. Entretanto, cabe ressaltar que, como uma reforma parcial, a RSB alcançou importantes conquistas, como o reconhecimento do direito universal à saúde, incluído na Constituição de 1988, a primeira constituição que tem uma seção sobre a saúde, e o reforço da noção de cidadania relacionada à seguridade social2,11.

Desde meados de 1970 até a redemocratização, não foi apenas o Movimento Sanitário 
que debateu a saúde como horizonte para reformas sociais. O ano de 1975, considerado pela Organização das Nações Unidas (ONU) o Ano Internacional da Mulher, é reconhecido, por algumas feministas, como marco importante de organização e reorganização das ações dos movimentos no Brasil12-14 e as questões relacionadas com a saúde compreendidas como fundamentais não poderiam ficar de fora ${ }^{6}$. Nesse cenário, ao menos duas perguntas emergem: existiram diálogos entre esses dois movimentos? Alguns estudos e documentos encontrados apontam que sim, mas como esses foram estabelecidos? Dessa forma, este ensaio objetiva apresentar algumas reflexões iniciais sobre as relações estabelecidas entre os movimentos feministas e sanitário, tema ainda pouco explorado, especialmente, quando consideramos o período de 1975 a 1988 ${ }^{15,16}$.

\section{Considerações sobre as relações entre os movimentos feministas e o Movimento Sanitário no Brasil}

Os movimentos feministas podem ser definidos como movimentos coletivos de luta das mulheres por direitos e por emancipação. A própria diversidade que constitui os movimentos feministas dificulta uma definição consensual17,18. Existem diversas configurações dos feminismos no Brasil18, assim como em outros países ${ }^{17}$, que se caracterizam por questões teórico-metodológicas, ideológicas e culturais distintas, entre outros aspectos. Temos como exemplos os feminismos do Sul e decoloniais, negro, indígenas, radicais, liberais e marxistas etc. ${ }^{18}$. Entretanto, alguns aspectos aparecem comuns nas diferentes ações sociopolíticas que se autointitulam como feministas: o reconhecimento da opressão específica vivida pelas mulheres, a divisão desigual dos poderes nas sociedades e a certeza de que as diferenças nas relações entre homens e mulheres não estão inscritas na natureza, e, sim, na organização sociopolítica das sociedades, sendo, portanto, passíveis de mudança ${ }^{12,17}$.

Existe uma distinção, ainda hegemônica, que foi realizada por algumas historiadoras e feministas da América do Norte e da Europa, dos movimentos feministas a partir de períodos históricos denominados como ondas. De maneira bastante sucinta, a primeira onda, segunda metade do século XIX e início do século $\mathrm{XX}$, corresponderia às lutas pelo direito ao voto. Na segunda onda, metade da década de 1960 e começo dos anos 1970, enfatizava-se que é impossível a igualdade em uma sociedade patriarcal e que o 'privado é político'. Críticas relacionadas a essa divisão têm sido feitas, por ser uma forma de historiografia lacunar que termina por apagar parte da história dos feminismos ${ }^{\mathbf{1 7}}$. Considerando essas críticas, optou-se por não utilizar tal divisão. Contudo, é importante mencionar que, dentro da dinamicidade social e da pluralidade que envolve os movimentos feministas, foram identificadas a terceira e a quarta ondas ${ }^{\mathbf{1 8}}$.

Em meados da década de 1970, os feminismos brasileiros se reorganizaram sendo influenciados pelas experiências dos feminismos internacionais. Foram formados grupos de reflexão e de autoconsciência, especialmente no eixo Rio-São Paulo, por mulheres, predominantemente, de estratos sociais médios, profissionais, intelectualizadas, que tinham retornado dos Estados Unidos e da Europa, onde tinham entrado em contato com as ideias feministas ${ }^{\mathbf{1 3}}$. Segundo Pinto ${ }^{\mathbf{1 3}}$, algumas mulheres que fizeram parte desses grupos vão adquirir, posteriormente, uma projeção nacional. A hegemonia delas no movimento acabou produzindo exclusões e supressão da diversidade dos feminismos no Brasil, e o movimento dessa época passou a ser compreendido como de classe média e branco ${ }^{19}$.

Carneiro ${ }^{20}$ analisa como a violência contra as mulheres negras e indígenas e a violação de seus corpos pelos colonizadores produziram marcas históricas profundas, apagadas pelo mito da democracia racial. A autora aponta 
que essas experiências de múltiplas opressões não foram consideradas pelo discurso clássico dos feminismos no Brasil e questiona:

Quando falamos do mito da fragilidade feminina, que justificou historicamente a proteção paternalista dos homens sobre as mulheres, de que mulheres estamos falando? Nós, mulheres negras, fazemos parte de um contingente de mulheres, provavelmente majoritário, que nunca reconheceram em si mesmas esse mito, porque nunca fomos tratadas como frágeis. Fazemos parte de um contingente de mulheres que trabalharam durante séculos como escravas nas lavouras ou nas ruas, como vendedoras, quituteiras, prostitutas 20(1).

Críticas relacionadas com a ausência de reconhecimento das articulações entre classe e raça foram realizadas pelas feministas negras, demonstrando tensões e conflitos dentro dos feminismos nacionais ${ }^{21}$. Foge ao alcance deste ensaio analisar de forma mais aprofundada tais tensões. Contudo, é fundamental reconhecê-las e compreender que as dinâmicas dos movimentos feministas envolvem disputas com convergências e divergências entre os diferentes grupos $^{19}$. Nesse período, a pauta de luta que pode ser considerada como aglutinadora, pois perpassava as experiências de, praticamente, todas as mulheres (ainda perpassa), é a reapropriação dos seus corpos. A consigna 'Nosso corpo nos pertence' se espalhou pelo mundo, desencadeando diferentes ações ${ }^{15}$. Foram criados diversos grupos e instituições não governamentais que trabalhavam na área da saúde, além de um amplo movimento popular de bairro composto, sobretudo, por mulheres com maior ou menor influência de ideias feministas. Os feminismos colocam uma posição alternativa ao debate populacional vigente expresso nas posições 'natalistas' e 'controlistas', formulando a noção de direitos reprodutivos ${ }^{22}$ :

Durante os anos 60 e início dos 70, a posição oficial do Brasil tendia ao natalismo.
Influenciado pela Igreja Católica, amparado nas elevadas taxas de crescimento do PIB verificadas durante o 'milagre econômico', e em preocupações militares geopolíticas de ocupação territorial, o governo descartava as posições neomalthusianas prevalentes em países do hemisfério norte, ao mesmo tempo em que fazia 'vista grossa' às entidades de planejamento familiar que operavam no país ${ }^{23(27) .}$

O crescimento populacional começou a ser considerado, a partir da década de 1950 , como um problema para o desenvolvimento econômico dos países do denominado primeiro mundo, principalmente, os Estados Unidos. Existia a preocupação que uma explosão demográfica aumentasse o consumo e assim provocasse a escassez de matérias-primas para as indústrias estadunidenses, dificultando seus projetos políticos e econômicos. O neomalthusianismo, antes sem muito espaço no Brasil, vai ganhando força à medida que o modelo econômico nacional arrefece e a influência estadunidense aumenta com a difusão de ideias de que por meio do controle demográfico se alcançaria um bom desenvolvimento econômico e social, diminuindo a pobreza ${ }^{11,16}$. As feministas negras denunciaram essas práticas 'controlistas', neomalthusianas, como racistas, já que realizaram a esterilização em massa das mulheres negras e pobres ${ }^{21}$. É neste contexto adverso que a noção de direito ao próprio corpo foi sendo construída.

Apesar de ter sofrido influências das experiências internacionais, mais especificamente, os feminismos franceses e estadunidenses ${ }^{19}$, grande parte dos grupos feministas da década de 1970 estava vinculada a organizações de influência marxista que faziam oposição à ditadura militar, isso levou o movimento a adquirir características próprias ${ }^{24}$. O novo marco de direitos sofre uma releitura na América Latina, busca se afastar da concepção liberal e individualista, almejando compreender os direitos reprodutivos como também sociais ${ }^{22}$.

Corrêa e Petchesky ${ }^{25}$ definem os direitos sexuais $^{26}$ e direitos reprodutivos em termos 
de poder e recursos. O poder estaria atrelado à capacidade de tomar decisões a partir de informações seguras sobre o processo reprodutivo e a sexualidade, e os recursos como tudo aquilo que é necessário para a concretização destas decisões. As autoras propõem quatro princípios que fundamentam os direitos sexuais e direitos reprodutivos: integridade corporal, autonomia pessoal, igualdade e diversidade. Entretanto, enfatizam que:

Os direitos sexuais e reprodutivos (ou quaisquer outros), compreendidos como 'liberdades individuais' e 'escolhas', não têm sentido, especialmente para grupos sociais mais pobres privados de direitos - quando estão ausentes as condições que permitem seu exercício. Estas condições constituem os direitos sociais e envolvem uma política de bem-estar social, segurança pessoal e liberdade política, elementos essenciais para a transformação democrática da sociedade e para a abolição de injustiças raciais, étnicas, de gênero ou classe 25(149-150).

Uma discussão importante nesse campo traz a necessidade de demarcar as especificidades para sexualidade e reprodução, desde sua construção enquanto saúde sexual e saúde reprodutiva, até sua constituição como direito humano. Os direitos sexuais fruto dos debates feministas e dos movimentos LGBTQI+ vêm demarcar necessidades com relação ao direito ao prazer e o livre exercício das sexualidades. Sua separação dos direitos reprodutivos é uma estratégia necessária para demarcar que o exercício das sexualidades não deve estar atrelado à reprodução. Como tradicionalmente as mulheres foram colocadas no lugar da procriação e do cuidado materno como destino, estas análises devem ser consideradas. Além disso, as comunidades LGBTQI+ também podem vivenciar suas sexualidades sem a necessidade desta relação direta ${ }^{26}$.

De acordo com Ávila ${ }^{6}$, os movimentos feministas, ao formularem a noção de direitos reprodutivos, estariam projetando um novo modelo de sociedade que exige reformas sociais e alarga o campo da cidadania, e da democracia. Para a autora, os direitos reprodutivos têm que ser compreendidos dentro de uma dinâmica histórica dos feminismos, em que a ideia do específico como isolado ou separado deve ser superada e os conceitos e princípios devem servir como base de referência para as redefinições da política e das condições socioeconômicas não só da vida das mulheres, mas de toda a sociedade, comprometidos com a transformação das desigualdades sociais.

Nessa dinâmica histórica, foram realizados vários eventos, incluindo, em 1984, o I Encontro Nacional de Saúde em Itapecerica da Serra, São Paulo ${ }^{15}$. Esse encontro reuniu grupos de mulheres e feministas de diferentes estados, que elaboraram a Carta de Itapecerica ${ }^{27}$. Documento considerado marco para algumas mulheres e feministas que militavam na área da saúde, a Carta ${ }^{27}$ foi o primeiro registro público realizado pela sociedade civil, que apresentava a noção de saúde integral da mulher ${ }^{16}$.

\section{A Carta de Itapecerica}

$\mathrm{Na} \mathrm{Carta}{ }^{27}$, dividida em duas partes, as mulheres apresentam uma série de denúncias tanto em caráter mais geral, relacionadas com as crises socioeconômica e sanitária em que vivia o Brasil, quanto sobre as especificidades das mulheres. Trazem algumas análises sobre o sistema de saúde, criticando o seu modelo privatista e medicalizante que não priorizava ações de prevenção e educação, não sendo adequado às necessidades da população. No que se refere às especificidades, o documento denuncia as condições precárias de atendimento às mulheres, sobretudo, as de estratos sociais baixos e sua visão reducionista da mulher como apenas reprodutora. Há o repúdio às ações 'controlistas' do Estado, com as esterilizações em massa, principalmente, das mulheres negras, ideias eugênicas ${ }^{21}$, e as justificativas fundamentadas no neomalthusianismo:

[...] as falsas soluções que propõem a implantação de um programa de planejamento familiar de cunho controlista, visando a 
erradicação da pobreza no país. A miséria reinante no Brasil, como nos demais países do Terceiro Mundo não é resultado de uma 'explosão demográfica', e sim fruto de modelo econômico concentrador de renda27(2-3).

Na segunda parte da Carta ${ }^{27}$, encontramos as propostas que se iniciam com uma conceitualização de saúde. Para as mulheres, o conceito de saúde em voga focalizava o indivíduo e a doença, enfatizando apenas os aspectos biológicos. Assim, propõem um conceito de saúde que considere sua dinamicidade e a interação entre os aspectos individuais, sociais, sexuais e de classe, sendo o processo saúde/doença compreendido a partir da análise das condições de vida. Apontam que as restrições sociais que impõem às mulheres o lugar de reprodutora, excluindo-as das decisões sobre os próprios corpos, acarretam problemas específicos, justificando a necessidade de um programa de saúde integral da mulher, que considere todos os ciclos biológicos e o contexto sociocultural. Reivindicam a participação das mulheres em todo processo de elaboração, implantação e fiscalização dessas ações e, assim, realizam uma defesa veemente do Programa de Assistência Integral à Saúde da Mulher (Paism) ${ }^{\mathbf{2 8}}$.

$\mathrm{Na} \mathrm{Carta}{ }^{27}$, notamos como existem análises e propostas que dialogavam com a RSB como, por exemplo, as críticas ao sistema de saúde e a concepção de saúde, então hegemônica. Podemos interpretar esse fato como um indicativo do trânsito de pessoas entre esses dois movimentos. Isso fica mais evidente em textos que analisam a criação e posterior tentativa de implantação do Paism ${ }^{28}$, no início da década de 1980 4,11,22,29-31, considerado a primeira política pública de saúde que traz a integralidade, um dos princípios finalísticos do SUS ${ }^{32}$.

\section{O Paism}

Em 1984, o Paism 22,28,31 foi anunciado pelo Ministério da Saúde como uma nova e diferenciada abordagem da saúde das mulheres.
Até aquele momento, a atenção à saúde das mulheres no Brasil referida nas políticas públicas estava relacionada, exclusivamente, com o aspecto materno-infantil. $\mathrm{O}$ foco principal dos diversos programas de saúde era realizar intervenções nos corpos das mulheres/mães, com o objetivo de garantir o nascimento de crianças que fossem adequadas às necessidades da reprodução social4,11,29.

O Paism ${ }^{28}$ foi elaborado por um grupo que reuniu sanitaristas, pesquisadores/as, feministas e representantes do Ministério da Saúde. As inovações não se referiram apenas aos conteúdos e propostas do programa, mas também era a primeira vez que um programa voltado para as mulheres tinha as próprias mulheres organizadas como interlocutoras privilegiadas, participando ativamente do seu planejamento, implantação e fiscalização $0^{4,22,29}$. Entretanto, como analisam Osis $^{\mathbf{3 1}}$ e D'Oliveira ${ }^{22}$, o Paism ${ }^{\mathbf{2 8}}$ continha um paradoxo. Ao mesmo tempo que representava algo inovador, surgiu em um contexto adverso, o do regime militar (mesmo que no seu ocaso) e também era a primeira vez que o Estado brasileiro propunha, de maneira explícita, um programa sobre a regulação da fecundidade, o que provocou suspeita sobre suas reais intenções.

O programa não recebeu o apoio imediato nem unânime dos movimentos feministas. Houve uma divisão: algumas acusavam o Paism $^{\mathbf{2 8}}$ de ser um programa com nova roupagem 'controlista', havia uma desconfiança sobre a proposta contraceptiva assumida pelo Estado, e o de se engajar em sua implantação, buscando assegurar a contextualização dessa proposta na perspectiva dos direitos reprodutivos. Apesar dessa divisão, a maior parte dos movimentos feministas aderiu à segunda opção, compreendendo-a como uma possibilidade de interferir no direcionamento que as políticas públicas destinadas à saúde das mulheres poderiam adquirir ${ }^{22}$.

Em 1986, o Paism ${ }^{28}$ foi definido pelo Instituto Nacional de Assistência Médica da Previdência Social (Inamps) como referência para a atenção às mulheres. Foram elaboradas estratégias para a implantação do programa que refletiam a 
articulação do Inamps com o Ministério da Saúde por meio das Ações Integradas de Saúde (AIS). No Paism ${ }^{28}$, encontra-se um conjunto de princípios e de diretrizes programáticas, que engloba os diferentes momentos dos ciclos de vida e situações de saúde das mulheres, incluindo, os temas relacionados com a reprodução. Sobre o planejamento familiar, afirma a livre escolha, preconizando que as pessoas não se submetam a riscos para a saúde em consequência da procriação e da anticoncepção. Tendo como propósito a garantia da autonomia na escolha dos métodos contraceptivos, são valorizadas práticas de educação em saúde e sexualidade, compreendidas como potentes ferramentas para a produção de informações que promovam a capacidade crítica das mulheres para a eleição dos métodos e que a atenção ao planejamento familiar seja realizada dentro da atenção à saúde, dessa forma, sob as diretrizes do princípio da integralidade $\mathbf{4 , 2 8 , 3 0}$.

Entretanto, não abordou a questão do aborto como um direito reprodutivo das mulheres ou mesmo pressionou para que fosse cumprida a lei ${ }^{23}$. No Brasil, a prática do aborto é considerada crime como consta nos arts. 124 a 127 do Código Penal de 1940. Em duas situações, não é passível de penalização: quando a gravidez representa risco de morte para a mulher e quando a gravidez é resultado de violência sexual, e em 2012, o Supremo Tribunal Federal (STF) decidiu autorizar as mulheres que assim o desejarem a interromper a gravidez em casos de fetos anencéfalos, sem que a prática configurar aborto criminoso. Tal omissão no Paism ${ }^{\mathbf{2 8}}$ pode ser interpretada como uma estratégia dos movimentos feministas para não colocar em risco as alianças políticas com outros movimentos sociais e com a Igreja Católica progressista, na luta pela redemocratização $0^{33}$.

Osis $^{31}$ analisando a história do Paism ${ }^{28}$ e o seu significado social, conclui que o programa foi precursor, inclusive no cenário internacional, ao ter como proposta o atendimento à saúde reprodutiva das mulheres no âmbito da atenção integral à saúde, e não mais restrita às ações voltadas para o planejamento familiar. A nova visão proposta pelas feministas sobre a integralidade compreendia a mulher como indivíduo e sujeita de direitos, percebida como uma totalidade, e não reduzida a um corpo reprodutivo individual ou populacional. Nessa perspectiva, ainda solicitavam a democratização do saber médico, a consideração dos saberes das mulheres e reivindicavam o direito ao acesso universal à saúde e aos cuidados médicos ${ }^{4,22}$.

O Paism ${ }^{\mathbf{2 8}}$ surge em um período de efervescentes mudanças no campo da saúde, e sua implantação estava condicionada a uma reestruturação do modelo assistencial ${ }^{11}$. Exigia a configuração de uma rede de serviços de saúde com acesso universal, hierarquizada e regionalizada, o que refletia as proposições contidas na $\mathrm{RSB}^{\mathbf{4}, 22}$. Costa ${ }^{30}$ pontua as conquistas do Movimento Sanitário no que diz respeito à consagração da saúde como direito universal e dever do Estado, como consta na Constituição, e dos movimentos feministas em terem mudanças nas concepções sobre os lugares das mulheres, refletidas, mesmo que apenas no plano formal, na definição sobre saúde das mulheres. Entretanto, segundo D'Oliveira ${ }^{22}$, as articulações entre essas duas fontes, Feminismos e Reforma Sanitária, não foram realizadas de maneira harmônica:

\begin{abstract}
A priorização, elemento essencial para a proposta médico-sanitária, e a integralidade, ponto básico do feminismo, tinham em comum o estímulo à ampliação da cobertura assistencial, mas com lógicas diversas. Enquanto as mulheres pediam o acesso ampliado a serviços com nova qualidade e renovadas relações de poder, a Reforma Sanitária pensava em um acesso ampliado com racionalização das ações do ponto de vista médico sanitário, o que implicaria, em tese, em priorização, com escolhas baseadas, sobretudo, no saber médico 22(108-109).
\end{abstract}

Para Ávila e Corrêa ${ }^{15}$, desde o início, questionamentos sobre o saber/poder médico estiveram presentes nas reflexões e reivindicações 
dos movimentos feministas. As concepções de saúde e assistência à saúde das mulheres, nas análises das feministas, estavam fundamentadas em uma concepção de natureza feminina compreendida como frágil, descontrolada e direcionada exclusivamente à reprodução social. O saber/poder médico produzia um disciplinamento do corpo feminino, bem como justificava a hierarquia entre os sexos, em que as mulheres ocupavam (ainda ocupam) o lugar de inferioridade. A saúde, assim, emerge no cenário dos feminismos como um espaço para mostrar como a procriação era um lugar de aprisionamento e de redução da dimensão humana das mulheres ${ }^{4,15}$.

Essas ideias, para além do Paism²8, parecem ter circulado no evento emblemático do Movimento Sanitário, a VIII Conferência, já que ocorreu, pela primeira vez, uma mesa sobre a saúde das mulheres ${ }^{\mathbf{2 3}}$. No entanto, em seu relatório ${ }^{8}$, não encontramos menção a elas, ou seja, apesar da conquista do espaço de debate, as pautas feministas não foram incluídas no documento final, nem mesmo foram consideradas na concepção ampliada de saúde. Vaitsman ${ }^{\mathbf{3 4}}$, ao analisar a concepção de saúde da VIII Conferência, assinala que essa definição, apesar de reconhecer a importância de aspectos como liberdade, meio ambiente, educação e lazer, não restringindo a saúde ao econômico, os reduz à determinação das formas de organização social da produção. Aponta que a saúde ou sua ausência não seria apenas o resultado das relações estabelecidas no processo social de produção. Embora as formas de organização social de produção gerem desigualdades, esse aspecto não deveria ser considerado como o principal ou mesmo o único determinante das desigualdades sociais e do processo saúde/doença.

Destaca que existem outras dimensões que produzem desigualdades, como gênero, raça, idade etc., que, combinadas com as relações de classe, produzem diferenças nos modos de vida e, consequentemente, nos processos saúde/doença:
A existência de saúde, que é física e mental - está ligada a uma série de condições irredutíveis umas às outras. Um conceito ampliado não poderia então considerar saúde só como resultante das formas de organização social da produção. Pois é produzida dentro das sociedades que, além da produção, possuem certas formas de organização da vida cotidiana, da sociabilidade, da afetividade, da sensualidade, da subjetividade, da cultura e do lazer, das relações com o meio ambiente ${ }^{34(171)}$.

Tais análises nos remetem a uma problemática que é recorrentemente apresentada por diferentes autoras, a conjugação das denominadas lutas 'específicas' com as tidas 'questões mais amplas'12-15. As dificuldades em superar essa dicotomia parecem ter marcado as relações entre os movimentos feministas com outros movimentos sociais, incluindo o sanitário. Como discorre Teles ${ }^{\mathbf{1 2 ( 6 3 )} \text { : }}$

A luta pela libertação da mulher não devia em nenhum momento ser desvinculada da busca de soluções dos problemas mais gerais da sociedade. Mas em raríssimas oportunidades as forças políticas que se propõem a travar as lutas gerais elegeram a questão da mulher como fundamental para o desenvolvimento do próprio processo de libertação do povo.

A luta geral que pode ser representada pela redemocratização e, no caso da saúde, pela democratização da saúde, para alguns setores, não se relacionava com as lutas feministas. Argumentos de que as pautas das mulheres enfraqueceriam e/ou dividiriam as lutas pelas 'causas maiores' e que as transformações sociais mais amplas desencadeariam mudanças nos modos vida, provavelmente, foram trazidos como justificativas, pois tais posicionamentos eram comuns mesmo entre as forças progressistas $^{\mathbf{1 2 - 1 5}}$. Resta-nos questionar como a RSB poderia alcançar uma ampla transformação social sem considerar as denominadas especificidades, gênero, raça, etnia, sexualidades etc., já que estas são dimensões sociais importantes 
que constituem a vida cotidiana das pessoas, produzindo diferentes desigualdades que se conectam e, ao mesmo tempo, vão além da organização social da produção. A denominada especificação deve ser compreendida como uma complexificação do olhar sobre o/a sujeito/a de direito, um distanciamento de uma visão de ser humano abstrata. Ela acentua e concretiza as diferenças, considerando os diversos marcadores sociais que, ao longo do tempo, vêm delimitando experiências de maior ou menor cidadania ${ }^{23}$.

Os desafios em colocar no processo de democratização da saúde e redemocratização política o reconhecimento das mulheres como sujeitas de direito e com necessidades específicas se faziam presentes em diferentes espaços $^{4,15}$. É dentro desse campo de correlações de forças conservadoras e progressistas não muito favoráveis às agendas feministas que os movimentos de mulheres e feministas atuaram, de maneira bastante ativa, na elaboração da Nova Constituição. A estratégia principal utilizada, mesmo não tendo sido consensual, foi de ocupar e qualificar com conteúdos feministas os espaços institucionais que estavam sendo (re)organizados no período de transição democrática ${ }^{15,23}$.

\section{A Nova Constituição}

Em 1985, foi criada, pelo governo federal, uma conquista do movimento de mulheres e feministas, um espaço institucional importante: 0 Conselho Nacional dos Direitos da Mulher (CNDM). No Conselho, as mulheres puderam organizar suas reinvindicações e acompanhar de perto os debates na Assembleia Nacional Constituinte $\mathbf{1 2}^{\mathbf{2}, \mathbf{1 3}, \mathbf{1 5}}$. Um cartaz que fora distribuído com os dizeres 'Constituinte para valer tem que ter palavra de mulher' exemplificava a mobilização das mulheres ${ }^{\mathbf{2 3}}$. Além de realizar campanhas para que os direitos das mulheres fossem incorporados na nova Constituição, foi o CNDM que promoveu o encontro em que grupos feministas e de mulheres elaboraram a 'Carta da mulher brasileira aos constituintes'.
O documento emblemático foi distribuído para os constituintes e era composto por duas partes. Na primeira parte, estavam descritas propostas mais amplas, que ultrapassavam as necessidades específicas das mulheres, com a defesa da justiça social, da reforma agrária, do ensino público e gratuito, a criação do SUS, entre outros temas. Já na segunda parte, estão apresentadas as reinvindicações das mulheres no trabalho, na saúde, nas relações de conjugalidade etc. ${ }^{13}$.

Pitanguy ${ }^{\mathbf{2 3}}$ destaca duas proposições importantes da carta, no que se refere à saúde: a defesa da saúde como um direito de todos e dever do Estado e que a saúde das mulheres não se restringe à dimensão materno-infantil. Os princípios da atenção integral presentes no Paism ${ }^{\mathbf{2 8}}$ foram reafirmados, da mesma forma que se combatia um modelo de regulação da fertilidade que fosse realizado de maneira coercitiva por instituições públicas ou privadas, que impusesse ou mesmo negasse o acesso aos métodos contraceptivos.

Durante o processo da constituinte, o CNDM enviou mais de 120 propostas e emendas populares elaboradas por diferentes entidades de mulheres e feministas ao Congresso Nacional, demonstrando como as mulheres estavam articuladas e ativas em todo o processo de construção da nova Constituição ${ }^{\mathbf{1 3 2} 23}$. As propostas foram, quase todas, incorporadas no texto da Constituição de 1988, e pela primeira vez foi reconhecida a igualdade jurídica entre homens e mulheres. No que se refere à saúde, vale a pena destacar a importância da atuação dos movimentos feministas que impediu retrocessos na lei relacionados com os direitos reprodutivos, especificamente, com o aborto. Mesmo não sendo colocada explicitamente a questão da legalização nos documentos produzidos, as feministas conseguiram garantir que não ocorressem mudanças na legislação ${ }^{33}$. Na época, também existia uma bancada religiosa conservadora, que pretendia introduzir a premissa do ‘direito a vida desde a concepção’, o que significaria retrocessos na lei'12,23.

A Constituição de 1988 não estabelece o direito à vida desde a concepção e garante o direito dos cidadãos e cidadãs de decidirem 
livre e responsavelmente sobre o número, o espaçamento e a oportunidade de ter filhos/ as, estabelecendo o planejamento reprodutivo (planejamento familiar, como escrito na Constituição) como um direito das pessoas e conferindo ao Estado o dever de prover os meios e os recursos necessários para tal15,35. Também passa a reconhecer a violência doméstica como um problema social e que o Estado deve construir mecanismos para combatê-la ${ }^{12}$.

Resultante do mais abrangente e democrático pacto estabelecido na história brasileira, a Constituição atual não se originou de uma ruptura completa com o regime militar. No processo da constituinte, diferentes forças democratizantes participaram, desde aquelas vinculadas à ditadura até as progressistas, que se opuseram ao autoritarismo. Em um contexto nacional marcado pela desconfiança, fragmentação política e ausência de uma visão hegemônica sobre os rumos do País, e em uma conjuntura internacional adversa com a agenda neoliberal a todo vapor, a Constituição de 1988 configurou-se como o pacto social do possível, com conquistas importantes, mesmo que no plano formal, relacionadas com os princípios da seguridade social e da universalização $0^{36,37}$.

Ainda dentro desse período, é importante mencionar que, anterior à promulgação da Constituição e como desdobramento da VIII CNS, aconteceu, em 1986, a I Conferência Nacional de Saúde e Direitos da Mulher. O encontro organizado pelo CNDM, contando com a colaboração dos movimentos de mulheres de várias partes do país e com o apoio do Ministério da Saúde, reafirmou os princípios da 'Carta das Mulheres Brasileiras aos Constituintes' e as diretrizes do Paism ${ }^{28}$, articulando-as às conclusões da VIII Conferência, e, consequentemente, à necessidade de uma Reforma Sanitária 15,23,38. Para Pitanguy ${ }^{23}$, dentre os aspectos discutidos na Conferência, dois pontos merecem destaque: uma proposta de legalização do aborto e a denúncia do abuso das esterilizações.

A atuação dos movimentos feministas e de mulheres foi, portanto, fundamental para as conquistas dos direitos consagrados na
Constituição na área da saúde tanto no que se refere às especificidades das mulheres quanto às denominadas questões mais amplas. Diferentes autoras, ao analisarem a atuação dos movimentos nesse período, destacam como as ações realizadas pelas mulheres e feministas estavam implicadas com a luta pela redemocratização do país e democratização da saúde, por conseguinte, com a construção de um projeto de sociedade democrático e comprometido com a justiça social, que também incluísse as pautas das agendas feministas ${ }^{\mathbf{1 5 , 2 3 , 2 4}}$.

\section{Comentários finais}

As reflexões iniciais tecidas neste ensaio indicam que existiram diálogos entre os movimentos feministas e sanitário. Identificamos propostas defendidas pela RSB nos documentos produzidos pelo ou com a participação dos movimentos de mulheres e feministas ${ }^{\mathbf{2 7}, 28,38}$, sendo a mais ilustrativa a formulação e tentativa de implementação do Paism ${ }^{28}$. Costa e Aquino ${ }^{4}$ analisam como o Paism ${ }^{28}$ resultou de interesses convergentes entre os movimentos feministas e sanitário. A nova abordagem da política de saúde das mulheres apresentava propostas que ampliavam e davam forma ao conceito de integralidade, tentando incorporar ações programáticas integradas que fossem mais horizontais e descentralizadas, além de assumir uma visão global da saúde das mulheres, antes restrita à sua dimensão reprodutiva. $\mathrm{O}$ próprio recuo estratégico relacionado com a legalização do aborto ${ }^{33}$ demonstra o engajamento dos movimentos feministas em promover articulações com outros movimentos sociais, evitando-se temas polêmicos e possíveis rupturas.

A partir da pesquisa documental preliminar 4,6,11,15,22,23,27-30,38 encontramos uma busca incessante dos movimentos feministas na saúde para relacionar as necessidades específicas das mulheres com as denominadas 'questões mais amplas', exemplificadas pela implicação nas lutas pela redemocratização social e democratização da saúde. Por outro 
lado, não encontramos a preocupação com as necessidades das mulheres em textos que analisam a $\mathrm{RSB}^{1-3}$ e no relatório da VIII CNS ${ }^{8}$, evento emblemático para o movimento sanitário. O que essa omissão significou? Quais foram os motivos? Perguntas que só poderemos, talvez, responder entrevistando as pessoas autoras dessa história, o que assinala mais um limite deste ensaio e, ao mesmo tempo, são ideias para outros estudos, que podem também considerar outras conjunturas. No entanto, cabe aqui arriscar algumas interpretações.

Para além das dificuldades já mencionadas em conectar o 'específico' com o 'geral', tal circunstância parece também revelar outras tensões relacionadas com a construção de uma pauta aglutinadora. Podemos ter como exemplo o que Teles ${ }^{\mathbf{1 2}}$ descreveu sobre o que aconteceu no II Congresso da Mulher Paulista, em 1980. A autora relata que uma disputa pela hegemonia dos movimentos por diferentes forças políticas e filiações partidárias gerou conflitos que dificultaram a construção de uma atuação unitária entre os movimentos feministas e os partidos:

Estes tentavam impor sua linha programática ao movimento, desconsiderando por inteiro as singularidades das mulheres que se apresentam na família, no casamento, em relação à maternidade, ao aborto, à sexualidade, no trabalho, no processo de profissionalização e educação12(121).

Como não encontramos ainda estudos que analisem as relações estabelecidas entre os movimentos feministas e sanitário no período de 1975 a 1988, supomos que situação semelhante possa ter acontecido. Ademais, é preciso considerar que a busca por uma unidade de luta dentro dos próprios movimentos sociais já é algo bastante desafiante. Disputas internas sobre quais pautas e estratégias são as mais importantes fazem parte da heterogeneidade que caracteriza os diferentes movimentos sociais ${ }^{7}$, com suas correntes teóricas, filiações partidárias e ideológicas etc., incluindo os feministas ${ }^{\mathbf{1 2}-14}$ e o sanitário ${ }^{\mathbf{2} 3}$. Dessa forma, estabelecer pontos em comum envolve certamente conflitos. A questão que se coloca é como esses conflitos são compreendidos.

Segundo Mouffe ${ }^{39}$, o antagonismo e o conflito são inerentes à democracia. Ela defende a construção de um espaço agonístico público de contestação, em que diferentes projetos políticos hegemônicos possam ser confrontados:

Para ser aceito como legítimo, o conflito precisa assumir uma forma que não destrua o ente político. Isso significa que é preciso existir algum tipo de vínculo comum entre as partes em conflito para que elas não tratem seus oponentes como inimigos que devem ser erradicados nem considerem que suas pretensões são ilegítimas com a relação amigo/ inimigo 39(18-19).

A autora denomina de agonismo um tipo de relação em que os oponentes não são considerados como simples concorrentes, com interesses que podem ser negociados ou acomodados em um debate, porque, nesse caso, o antagonismo deixaria de existir. Na relação agonística, as partes conflitantes reconhecem que não existe uma solução racional para o conflito, mas também reconhecem a legitimidade de seus oponentes, que são percebidos como 'adversários', e não como um inimigo que deve ser eliminado. Mouffe 39 coloca que o modelo adversarial é imprescindível para a democracia, pois ajuda a manejar o antagonismo com a construção de canais políticos legítimos como, por exemplo, as instituições democráticas. Estas têm que garantir a expressão das vozes discordantes, já que, segundo a autora, isso reduziria a probabilidade de emergirem conflitos antagonísticos na política democrática.

A democracia moderna exige outra formulação da distinção nós/eles/as. Uma que aceite o pluralismo que a constitui e que mantenha sob controle o surgimento do antagonismo. Para isso, a política democrática tem que elaborar formas coletivas de identificação que mobilizem os afetos, as paixões como denomina 
Mouffe ${ }^{39}$, que sejam capazes de construir cadeias de equivalência de comuns e que, ao mesmo tempo, reconheçam o caráter hegemônico de todos os tipos de ordem social, que são estabelecidos em um contexto de contingência ${ }^{39}$.

Nessa perspectiva, Aquino ${ }^{40}$, refletindo sobre a construção do SUS e a equidade de gênero em saúde, assinala que existem diferentes projetos de sociedade em disputa que acabam provocando a busca por soluções que não devem se restringir apenas às técnicas, mas considerar, sobretudo, o âmbito político. Enfatiza que é impossível obter mudanças fora do projeto de SUS democrático, proposto pela RSB e consagrado na Constituição, da mesma forma sem a defesa do Estado laico, democrático e plural que considere as articulações entre gênero, classe social, raça, etnia e sexualidades, e suas implicações para a saúde.

Compartilhando de reflexões semelhantes Paim ${ }^{\mathbf{1 0}}$ propõe:

Considerando as peculiaridades da revolução passiva no Brasil que invadiu o processo da RSB, torna-se fundamental constituir sujeitos da práxis (sujeitos da resistência, novos servidores públicos, sujeitos transformadores), individuais e coletivos, capazes de defender o SUS, e sujeitos da antítese aptos em desequilibrar o binômio da conservação-mudança a favor das transformações, radicalizando a democracia e a RSB [...]. Diante das limitações dos partidos e do protagonismo dos movimentos sociais, a busca da hegemonia político-cultural e a luta pela radicalização da democracia implicam a construção de equivalências entre agendas e sujeitos coletivos, para além da contradição capital-trabalho10(1727).

Os desafios para realizar as propostas sugeridas por Paim ${ }^{10}$ são muitos, principalmente, em uma conjuntura como a atual de graves retrocessos relacionados com as conquistas democráticas, que englobam a saúde e os direitos reprodutivos. Assim, ao elaborar este ensaio, reconhecemos suas limitações e a complexidade da temática. Nos arriscamos a traçar essas pistas analíticas para explicitar os trânsitos/diálogos entre os dois movimentos sociais, as conquistas alcançadas e compreender, ainda que incipientemente, como essas relações foram estabelecidas. Esperamos que essas reflexões, mesmo que parciais, possam contribuir para a construção de estratégias que agreguem velhos/as e novos/as sujeitos/as concretos e plurais na luta pelo direito a saúde.

\section{Colaboradores}

Silveira PS (0000-0003-0621-6059)* contribuiu para a concepção, realização da pesquisa e elaboração do ensaio. Paim JS (0000-00030783-262X)* contribuiu para a concepção, elaboração do ensaio, revisão crítica do conteúdo e aprovação da versão final. Adrião KG (0000-0002-7411-425X)* contribuiu para a elaboração do ensaio e revisão crítica do conteúdo. 


\section{Referências}

1. Paim JS, Almeida-Filho N. Reforma Sanitária Brasileira em perspectiva e o SUS. In: Paim JS, Almeida-Filho N, organizadores. Saúde Coletiva: Teoria e Prática. Medbook; 2014. p. 203-209.

2. Paim JS. Reforma Sanitária Brasileira. Contribuição para a compreensão e crítica. Salvador: Edufba; Rio de Janeiro: Fiocruz; 2008.

3. Fleury S. Reforma Sanitária: múltiplas leituras, diálogos e controvérsias. In: Fleury S, organizadora. Teoria da Reforma Sanitária: diálogos críticos. Rio de Janeiro: Fiocruz; 2018. p. 15-30.

4. Costa AM, Aquino EL. Saúde da mulher na reforma sanitária brasileira. In: Costa A, Merchán-Hamann E, Tajer D, organizadores. Saúde, equidade e gênero. Brasília, DF: UnB; 2000. p. 181-202.

5. Sarti CA. Feminismo e contexto: lições do caso brasileiro. Cad. Pagu. [internet]. 2001 [acesso em 2018 fev 16]; 16:31-48. Disponível em: http://www.scielo.br/scielo.php?script=sci_arttext\&pid=S0104$-83332001000100003 \& \operatorname{lng}=$ pt\&nrm=iso.

6. Ávila MB. Modernidade e cidadania reprodutiva. Rev. Estud. Feministas. 1993; (2):382-393.

7. Gohn MG. Movimentos Sociais In: Ivo ABL, coordenador. Dicionário temático desenvolvimento e questão social: 81 problemáticas contemporânea. São Paulo: Annablume; 2013, p. 309-319.

8. Brasil. Ministério da Saúde; Conselho Nacional de Saúde. Relatório final da 8a Conferência Nacional de Saúde. Brasília, DF; 1986.

9. Heller A. Teoría de las necessidades em Marx. Letra; 1986.

10. Paim JS. Sistema Único de Saúde (SUS) aos 30 anos. Ciênc. Saud. Colet. [internet]. 2018 [acesso em 2019 jan 20]; 23(6):1723-1728. Disponível em: http://www. scielo.br/scielo.php?script=sci_arttext\&pid=S1413$-81232018000601723 \& \operatorname{lng}=$ pt\&nrm=iso.
11. Costa AM. Desenvolvimento e implantação do Paism no Brasil. In: Giffin K, Costa SH, organizadoras. Questões da saúde reprodutiva. Rio de Janeiro: Fiocruz; 1999. p. 319-335.

12. Teles MAA. Breve história do feminismo no Brasil. São Paulo: Brasiliense; 1999.

13. Pinto CR. J. Uma História do Feminismo no Brasil. São Paulo: Fundação Perseu Abramo; 2003.

14. Pedro J. Narrativas fundadoras do feminismo: poderes e conflitos (1970-1978). Rev. Bras. História. [internet]. 2006 [acesso em 2018 maio 15]; 26(52):249-272. Disponível em: http://www.scielo.br/scielo.php?script=sci arttext\&pid=S0102-01882006000200011.

15. Ávila MB, Corrêa S. O movimento de saúde e direitos reprodutivos no Brasil: revisitando percursos. In: Galvão L, Dáz J, organizadores. Saúde sexual e reprodutiva no Brasil: dilemas e desafios. São Paulo: Hucitec; 1999. p. 70-103.

16. Brito MAF. A influência de movimentos de mulheres nas políticas públicas para a saúde da mulher no Brasil - 1984 [dissertação]. Brasília, DF: Universidade de Brasília; 2014. 125 p.

17. Fougeyrollas-Schwebel D. Movimentos Feministas. In: Hirata H, Françoise Laborie, Hélène Le Doaré, et al., organizadoras Dicionário crítico do feminismo. São Paulo: Unesp; 2009. p. 144-149.

18. Holanda HB. Explosão feminista: arte, cultura, política e universidade. São Paulo: Companhia das Letras, 2018.

19. Adrião KG. Encontros do feminismo: uma análise do campo feminista brasileiro a partir das esferas do movimento, do governo e da academia [tese]. Florianópolis: Universidade Federal de Santa Catarina; 2008. $301 \mathrm{p}$.

20. Carneiro S. Enegrecer o feminismo: a situação da mulher negra na América Latina a partir de uma perspec- 
tiva de gênero. In: Ashoka Empreendimentos Sociais, Takano Cidadania, organizadores. Racismos contemporâneos. Rio de Janeiro: Takano; 2003. p. 49-58.

21. Damasco MS, Maio MC, Monteiro S. Feminismo negro: raça, identidade e saúde reprodutiva no Brasil (1975-1993). Rev. Estud. Feministas. [internet]. 2012 [acesso em 2019 ago 1]; 20(1):133-151. Disponível em: http://www.scielo.br/scielo.php?script=sci arttext\&pid=S0104-026X2012000100008\&lng=en\& nrm=iso\&tlng=pt.

22. D’Oliveira AFL. Saúde e Educação: a discussão das relações de poder na atenção à saúde da mulher. Inter. Comunic. Saúde, Educação. [internet]. 1999 [acesso em 2017 fev 8]; 3(4):105-122. Disponível em: http://www.scielo.br/scielo.php?script=sci arttext\&pid=S1414-32831999000100009\&lng=en\&n $\mathrm{rm}=\mathrm{iso} \& \mathrm{tlng}=\mathrm{pt}$.

23. Pitanguy J. O movimento nacional e internacional de saúde e direitos reprodutivos. In: Giffin K, Costa SH, organizadoras. Questões da saúde reprodutiva. Rio de Janeiro: Fiocruz; 1999. p. 19-38.

24. Sarti CA. O feminismo brasileiro desde os anos 1970: revisitando uma trajetória. Rev. Estud. Feministas. [internet]. 2004 [acesso em 2017 fev 1]; 12(2):3550. Disponível em: http://www.scielo.br/scielo. php?script=sci_arttext\&pid=S0104-026X2004000 $200003 \& \operatorname{lng}=$ pt\&nrm=iso $\&$ tlng $=$ pt.

25. Corrêa S, Petchesky R. Direitos sexuais e reprodutivos: uma perspectiva feminista. Physis [internet]. 1996 [acesso em 2017 jan 28]; 6(1/2):147-177. Disponível em: http://www.scielo.br/scielo.php?script=sci arttext\&pid=S0103-73311996000100008\&lng=pt\&n $\mathrm{rm}=\mathrm{iso} \& \operatorname{lng}=\mathrm{pt}$.

26. Corrêa S. Cruzando a linha vermelha: questões não resolvidas no debate sobre direitos sexuais. Horiz. Antropol. [internet]. 2006 [acesso em 2018 ago 19]; 12(26):101-121. Disponível em: http://www.scielo.br/scielo.php?script=sci_arttext \&pid=S0104$-71832006000200005 \& \operatorname{lng}=p t \& n r m=i s o \& t \operatorname{lng}=p t$.

27. Carta de Itapecerica. [Itapecerica da Serra/SP]; 1984.
28. Brasil. Ministério da Saúde. Assistência Integral à Saúde da Mulher: bases de ações programáticas. Brasília, DF: Ministério da Saúde; 1984.

29. Osis MJ. Atenção Integral à saúde da Mulher, o conceito e o programa: história de uma intervenção [dissertação]. Campinas: Universidade Estadual de Campinas; 1994. $118 \mathrm{p}$.

30. Costa AM. Participação social na conquista das políticas de saúde para mulheres no Brasil. Ciênc. Saúde Colet. [internet]. 2009 [acesso em 2017 jun 19]; 14(4):1073-1083. Disponível em: http://www.scielo.br/scielo.php?script=sci_arttext\&pid=S1413$-81232009000400014 \& \operatorname{lng}=$ pt\&nrm=iso\&tlng=pt.

31. Osis MJ. PAISM: um marco na abordagem da saúde reprodutiva no Brasil. Cad. Saúde Pública. [internet]. 1998 [acesso em 2017 ago 30]; 14(supl1):25-32. Disponível em: http://www.scielo.br/scielo.php?script=sci arttext\&pid=S0102-311X1998000500011\&lng=pt\&nr $\mathrm{m}=\mathrm{iso} \& \operatorname{lng}=\mathrm{pt}$.

32. Teixeira CF, Souza LEPF, Paim JS. Sistema Único de Saúde (SUS): a difícil construção de um sistema universal na sociedade brasileira. In: Paim JS, Almeida-Filho N, organizadores. Saúde Coletiva: Teoria e Prática. Rio de Janeiro: Medbook; 2014. p. 121-137.

33. Scavone L. Políticas feministas do aborto. Rev. Estud. Feministas. [internet]. 2008 [acesso em 2017 out 31]; 16(2):675-680. Disponível em: http://www.scielo.br/ scielo.php?script=sci_arttext\&pid=S0104-026X2008 $000200023 \& \operatorname{lng}=$ pt\&nrm=iso\&tlng=pt.

34. Vaitsman J. Saúde, Cultura e Necessidades. In: Fleury S, organizadora. Saúde Coletiva? Questionando a onipotência do social. Rio de Janeiro: Relume-Dumará; 1992. p. 157-173.

35. Ventura M. A questão do aborto e seus aspectos jurídicos. In: Rocha MIB, Barbosa RM, organizadoras. Aborto no Brasil e países do Cone Sul: panorama da situação e dos estudos acadêmicos. Campinas: Unicamp; 2009. p. 176-205.

36. Vieira OV, Barbosa AL. Do compromisso maximi- 
zador à resiliência constitucional. Novos estud. CEBRAP. [internet]. 2018 [acesso em 2019 jan 11]; 37(3): 375-393. Disponível em: http://www.scielo.br/scielo.php?script=sci_arttext\&pid=S0101$-33002018000300375 \& \operatorname{lng}=$ pt\&nrm=iso\&tlng=pt.

37. Cardoso JCP. A CF-1988 na Berlinda: trinta anos de disputas por um projeto nacional de desenvolvimento nos trópicos. Saúde debate. [internet]. 2018 [acesso em 2019 mar 6]; 42(esp3):18-32. Disponível em: http://www.scielo.br/scielo.php?script=sci arttext\&pid=S0103-11042018000700018\&lng=pt\&n $\mathrm{rm}=\mathrm{iso} \& \operatorname{lng}=\mathrm{pt}$.

38. Brasil. Ministério da Saúde; Conselho Nacional de Saúde. Relatório Final da I Conferência Nacional de Saúde e Direitos da Mulher. Brasília, DF; 1987.
39. Mouffe C. Sobre o político. São Paulo: WMF Martins Fontes; 2015.

40. Aquino EML. Para reinventar o parto e o nascimento no Brasil: de volta ao futuro. Cad. Saúde Pública. [internet]. 2014 [acesso em 2017 maio 25]; 30(supl1):810. Disponível em: http://www.scielo.br/scielo. php?script=sci_arttext\&pid=S0102-311X201400130 0002\&lng=pt\&nrm=iso.

Recebido em 10/04/2019

Aprovado em 07/08/2019

Conflito de interesses: inexistente

Suporte financeiro: não houve 